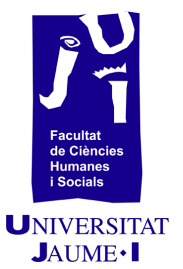

\title{
El arte de los títeres y sus aportaciones a la salud y la paz
}

en contextos de conflicto armado y posconflicto

Rebeca Castro Pinzón recaed@yahoo.es 
I. Resumen

Este trabajo busca identificar y analizar las sinergias entre el arte de los títeres, la salud sistémica y la paz imperfecta en contextos de conflicto armado y posconflicto. La mirada multisituada en el paradigma de la complejidad, la psicología sistémica y la teoría de paz imperfecta fundamentan este trabajo. Los sistemas abiertos, humanos y naturales, configuran entramados de intercambios comunicativos y relacionales con dinámicas conflictivas y capacidades de autorregulación y autorreajuste. En esta investigación, desde una perspectiva sistémica, el arte de los títeres se propone como una herramienta valiosa para la regulación pacífica de los conflictos y el empoderamiento pacífico de personas y grupos. A través de procesos de mediación e intervención con títeres, se activan y fortalecen capacidades y potencialidades resilientes que promueven bienestar y convivencia.

Palabras clave: psicología sistémica, arteterapia, teatro de títeres, resiliencia, convivencia.

\section{Introducción}

Este estudio nace desde el deseo y la necesidad de integrar las diferentes disciplinas que han marcado mi ejercicio profesional: la psicología y el arteterapia. El títere contiene los lenguajes simbólicos de la cultura, de las vivencias, de las costumbres y, como relator de la humanidad, contiene lo más profundo y performativo del ser humano. El arte en este estudio se entiende a través del títere, como una de las artes teatrales más complejas y completas, portador del lenguaje simbólico de orden superior que refleja la complejidad de los sistemas humanos y que promueve su evolución. En esta perspectiva, nos planteamos tres tareas principales que consideramos como nuestros objetivos en este trabajo.

\section{Objetivo principal}

Reflexionar sobre procesos de intervención y mediación con el teatro de títeres, que integran procesos psicológicos sistémicos y de paz imperfecta dentro del marco del pensamiento complejo, en su contenido y forma, donde se visibilicen las sinergias entre el arte, la salud y la paz. 


\subsection{Objetivos específicos}

Mostrar el universo del títere como elemento complejo para comprender su función y relación con la salud y la paz.

Delimitar el concepto de conflicto armado y posconflicto, describiendo los efectos de alteración y daño psico- y socioculturales, individual o colectivo, contexto en el cual se propone la intervención y mediación con el teatro de títeres.

Definir las sinergias entre el arte de los títeres, la salud sistémica y la paz imperfecta, que pueden evidenciarse en procesos de intervención y mediación con el teatro de títeres.

\section{Conflicto armado y posconflicto: contexto}

En este apartado se profundiza sobre el concepto de conflicto armado, como contexto poblacional con el cual trabajar procesos de salud sistémica y paz imperfecta, en procesos de intervención y mediación con el teatro de títeres. Dicho contexto presenta distinciones y evoluciones en las características humanas, sociales, en sus interpretaciones e implicaciones legales y políticas. Por tanto, se revisa el concepto de conflicto armado y posconflicto, y se explica la dinámica actual del enfrentamiento armado y los efectos durante o después en el posconflicto.

\section{1. ¿Por qué en conflicto armado y posconflicto?}

La delimitación del concepto de conflicto armado en este trabajo se debe a la evolución que ha tenido la guerra dentro y fuera de las fronteras mundialmente. La guerra como enfrentamiento entre naciones por defender sus fronteras e intereses económicos y sociales ha ido adquiriendo otros matices y formas de acción. En algunos casos, después del enfrentamiento y el conflicto resurge o bifurca hacía enfrentamientos militares de Estados con grupos armados discrepantes, en los que intervienen militarmente otras naciones, ya sea dando apoyo logístico, de inteligencia militar, político y económico, de acuerdo a sus intereses e internacionalizando el conflicto (Rodríguez, 2008: 12).

La dinámica interna de los países se ha visto afectada por la geopolítica del mundo y actualmente los conflictos internos de los estados son mayores que las guerras entre naciones. El enfrentamiento bélico entre grupos armados y el surgimiento de estos tiene varias razones: por desigualdad, religión, ideario político, 
recursos naturales, entre otros. Los enfrentamientos también se ven agudizados por la intromisión de otros intereses, como de grupos económicos, de otras naciones $\mathrm{o}$ de alianzas corporativas transnacionales, entre otros. Las nuevas guerras se pueden definir mejor en términos de conflictos armados diversos, múltiples, complejos y singulares, los cuales tienen por efecto el posconflicto (Rodríguez, 2008: 12).

El conflicto armado con sus modalidades, su vasto y prolongado efecto, ejerce en la población civil su mayor daño, e impacta destructivamente en la vida cotidiana y el tejido social de las poblaciones que lo sufren, durante y después, tras un largo tiempo de recuperación, al que se ha llamado posconflicto. En la vieja práctica del conteo de bajas militares durante la guerra, se daban cifras para cantar victoria o para declarar la derrota. No se nombraban, ni sumaban las bajas civiles, porque no tenían valor en su momento. Se estima que a inicios del siglo xx alrededor del $90 \%$ de las víctimas eran integrantes de los grupos armados $y$, a finales del mismo siglo, esta cifra se invierte. A partir de ahí, se considera que la población civil se convierte en uno de los objetivos y blancos fáciles del conflicto armado (Peñas et al., 2015: 613).

\subsection{Los alcances del conflicto armado y posconflicto}

En este apartado, presentamos los niveles de daño y afectación psicosocial en las personas o grupos que han vivido el conflicto armado, alterando las dimensiones humanas y de la convivencia en sociedad, que generan problemáticas o trastornos en ámbitos físicos, psíquicos, conductuales, relacionales y sociales. Dimensiones que, al verse afectadas, participan en el deterioro de otras áreas asociadas, agudizando los problemas personales y grupales.

El impacto del conflicto armado a niveles sociales y humanos es muy alto. En zonas devastadas y empobrecidas por el conflicto de grupos armados, la población sobrevive en condiciones muy precarias, incluso durante la lucha armada, experimentando intensos estados de caos, incertidumbre y terror colectivo. Las poblaciones son desplazadas y expropiadas de sus tierras, casas o comunidades, y con ello, de su sentido de vida. La violencia que viven los despoja de su cultura y universo simbólico con el que significan la vida cotidiana, y se destruyen los tejidos de solidaridad y confianza que vinculan al individuo, la familia, el grupo o la comunidad.

Progresivamente, el miedo los aísla, los encierra en su dolor y silencia cualquier intento de comunicación e interacción entre los individuos y el grupo. La precariedad y necesidad de supervivencia reducen las posibilidades de acción y se convierten en el único motor. Los espacios comunes que antes compartían ya no existen o han sido tomados por la violencia del conflicto armado; surgen y se intensifican los sentimientos de impotencia, abatimiento, 
desesperanza, apatía y victimización (Azam y Hoeffler, 2002, citados en Rodríguez, 2008: 12-13).

Peñas et al. (2015: 619-620) recopilan algunos datos de las esferas humanas y sus grupos etarios afectados por la violencia del conflicto armado, en una revisión de caso en 19 países en dicho conflicto armado. Esta información sale de proyectos de intervención y mediación con arte, realizados por algunas instituciones en estos países. Esta información se menciona en este trabajo por su utilidad, ya que da un panorama de las dimensiones vitales a trabajar en las intervenciones y mediaciones con títeres.

Tabla 1. Personas y grupos afectados por el conflicto armado y posconflicto

\begin{tabular}{|c|c|}
\hline \multirow[t]{3}{*}{ Víctimas } & $\begin{array}{l}\text { Con síntomas de estrés postraumático u otros } \\
\text { trastornos asociados }\end{array}$ \\
\hline & con discapacidades \\
\hline & de minas antipersona \\
\hline \multirow[t]{2}{*}{ Refugiados y en campamento } & poblaciones repatriadas \\
\hline & poblaciones desplazadas \\
\hline \multirow[t]{3}{*}{ Personas } & privadas de la libertad \\
\hline & con familiares de desaparecidos \\
\hline & en instituciones penitenciarias \\
\hline \multirow[t]{3}{*}{ Integrantes } & de grupos ilegales \\
\hline & de fuerzas armadas \\
\hline & y sus familias \\
\hline \multirow{5}{*}{$\begin{array}{r}\text { Personas (entre ellos jóvenes } \\
\text { y niños) }\end{array}$} & con riesgo a vincularse a grupos armados \\
\hline & secuestrados/as \\
\hline & esclavas/os sexuales \\
\hline & menores en riesgo social \\
\hline & huérfanos \\
\hline \multirow[t]{4}{*}{ Personas, jóvenes y niños } & residentes \\
\hline & estudiantes \\
\hline & escolarizados \\
\hline & desescolarizados \\
\hline \multirow[t]{3}{*}{ Grupos especiales } & Comunidades indígenas \\
\hline & Comunidades gitanas \\
\hline & y otras minoritarias \\
\hline \multirow[t]{4}{*}{ Personal y profesional } & maestros \\
\hline & promotores de derechos humanos y sociales \\
\hline & líderes locales \\
\hline & profesionales de la salud y otros \\
\hline
\end{tabular}

Fuente: elaboración propia, datos tomados de (Peñas et al., 2015: 619) 
En el contexto del conflicto armado y en el posconflicto, las personas y los grupos presentan problemáticas múltiples a todo nivel, que varían su aparición, presencia o cronicidad; modifican su escalada o superación debido a numerosas circunstancias y recursos individuales y/o colectivos (Peñas et al., 2015: 619).

Las dimensiones problemáticas personales y sociales se refieren a lo siguiente:

- Una importante situación de vulnerabilidad

- Dificultad al acceso o pérdida de recursos económicos, pobreza o de extrema pobreza, desempleo

- La fragilidad o inexistencia de redes de apoyo, desempleo

- Riesgo o víctimas de abuso sexual, abusos físicos, torturas, amputaciones, reclutamiento forzado, esclavitud

- Riesgo o presencia de problemas de salud, derivados en algún tipo de trastorno afectivo, de la conducta, antisocial o de estrés postraumático, enfermedad 0 estado crónico

- Con privación y desequilibrio ocupacional, aislamiento laboral, privados de la libertad

- Problemas de pérdida de identidad, alcoholismo, violencia doméstica, consumo de sustancias psicoactivas, dolor, muerte de familiares, discapacidad, deserción escolar

- Conflictos por choques culturales, falta de vivienda, escasez de elementos básicos, entre otros

Individualmente, además de compartirse las anteriores situaciones problemáticas, la clínica médica define uno de los trastornos más recurrentes en el marco del conflicto armado y el posconflicto, conocido como el trastorno de estrés postraumático. Clasificado y descrito en el Diagnostic and Statistical Manual of Mental Disorders (DSM-5) como un conjunto de síntomas clínicos que se presentan con alteraciones del comportamiento en personas que han estado bajo el estrés de la guerra o situaciones de alto riesgo, por la exposición a la muerte, lesión grave o violencia sexual, ya sea real o amenaza.

Este síndrome se manifiesta con ansiedad, trastornos de conducta, agresión física, miedo, aislamiento, sueños angustiosos, escenas retrospectivas, recuerdos intrusivos e involuntarios, entre otros. Todos estos signos y síntomas configuran un malestar psicológico intenso que afecta todas las esferas de la vida individual y de grupo, asociado también a otros trastornos, producto de la distancia del trauma o su proximidad, de la frecuencia con la que este se presenta y de su duración, tales como trastornos adaptativos, de alimentación, del sueño, de la conducta, depresión, psicosomático, etc. (American Psychiatric Association, 2013: 271). 
El impacto de la violencia directa e indirecta que genera el conflicto armado es amplio y profundo, y lo destroza todo a su paso. El conflicto armado se apropia de los procesos sociales y culturales de las comunidades o poblaciones afectadas, y se toma el espacio común y público, la voz y libertad de las personas, sus relaciones y tejidos sociales, los proyectos vitales y de futuro de individuos y grupos. El conflicto armado impone las relaciones jerárquicas de fuerza y de poder, las normaliza y destruye las estructuras sociales de igualdad y participación anteriores, que se basan en la confianza y la solidaridad de la comunidad (Rodríguez, 2008: 10).

\section{Características de una intervención y mediación con títeres}

En este apartado, se esbozan las condiciones de trabajo profesional para realizar una intervención y mediación con el teatro de títeres. En un ambiente, con unos recursos profesionales, humanos y materiales, con directrices, que contribuya a reestablecer los recursos resilientes de las personas y los grupos, generando procesos de paz imperfecta y salud sistémica. Parte del reto profesional y académico de esta investigación es aportar elementos para la intervención y mediación con el teatro de títeres, que generen procesos de trasformación social e individual para la reconstrucción de la vida en positivo y el empoderamiento pacífico, en contextos de conflicto armado o posconflicto. Procesos de intervención y mediación con títeres, donde las personas puedan alcanzar la supervivencia y trascenderla por la potenciación de sus propios recursos, capacidades y habilidades. Estos procesos de intervención son de necesaria implantación en dichos contextos de violencia, porque, como señala Cyrulnik (2016), la calidad de acogida de la sociedad y de los profesionales e intervinientes humanitarios es determinante para la superación del trauma.

Si bien hay unas condiciones generales en la población afectada por el conflicto armado y unas dinámicas intrínsecas a los procesos bio- y psicosociales que les acompañan, también hay condiciones particulares que definen a los individuos en este contexto. White y Epson (1993) resaltan que es el significado que se atribuye a los hechos lo que determina el comportamiento, lo que ayuda a las personas a organizar sus vidas para conseguir la supervivencia y superar los problemas que se derivan de la violencia, además del efecto que tienen esas exigencias de supervivencia sobre sus vidas y sobre las relaciones entre estas personas.

La fuerza de la vida se impone en estos contextos de dolor y necesidad, las personas buscan naturalmente el cuidado que alivia 
sus emociones. A través de habilidades comunicativas de seducción, energía, inteligencia, humor buscan formas de conectar con los otros para suplir sus necesidades y salir adelante, buscan amigos 0 personas con quien compartir y unir fuerzas para resolver problemas y encontrar soluciones a la cotidianidad (Berck, 2002: 52).

De manera resiliente, con los propios recursos, las personas van creando la base para la potenciación de sus capacidades y de las diversas capacidades que tiene el grupo. La capacidad humana de salir adelante se nutre de todos los elementos conscientes e inconscientes para dar el salto de la supervivencia a la vivencia. Un salto definitivo que es acompañado y reforzado por el grupo social (Bennegadi, 2016) y el equipo profesional que rodea a la persona en procesos de intervención y mediación con el teatro de títeres. Este paso de la supervivencia a la vivencia, como acto elevado de conciencia y acción, se acelera durante la intervención y mediación con el títere por la expresión emocional del sufrimiento, nombrando lo indecible y resignificando la experiencia del dolor para reactivar la vida psíquica, para que un individuo traumatizado por la violencia se reconstruya.

Hacer intervención y mediación con títeres a grupos afectados por la violencia del conflicto armado y en posconflicto tiene varios retos y compromisos. El compromiso más general tiene que ver con el paradigma desde el que se trabaje; por la extensión de elementos y factores del sistema humano y por la diversidad del conflicto armado, la perspectiva para su entendimiento y abordaje debe ser compleja, transcultural, holística y multisituada.

Esta intervención debe tener un enfoque centrado en el individuo y/o el grupo, su contexto, su historia, sus interacciones y relaciones; así mismo en las potencialidades y capacidades de los seres que forman parte del proceso y por lo que están dispuestos a aportar. La intervención debe tener un alto contenido psicoafectivo, de exploración y fortalecimiento emocional, significativo para todo participante. Un proceso que hace uso de los propios recursos y del grupo, donde el conjunto de los contenidos personales acelere y gestione procesos de resiliencia, en los que se potencien elementos y estrategias de empoderamiento para la superación, procesos movilizados por el profesional, por el grupo y por sí mismos (SimóAlagado, 2013).

Esta intervención y mediación con el teatro de títeres debe partir de un análisis cuidadoso de la situación, de las circunstancias y de los recursos. Es necesario hacerse preguntas que ayuden a esclarecer y dar información suficiente para iniciar un proceso de intervención con personas perturbadas por el conflicto armado y posconflicto. Preguntas como ¿Qué medio encontrar para comunicarse? ¿Cómo permitir la expresión a personas que están en estado de shock, confusión o abatimiento? ¿Qué lenguaje es adecuado para dar forma 
a lo confuso, protegido u oculto? Estos y otros cuestionamientos son fundamentales para empezar a entender y tender alternativas de acercamiento y abordaje con estas personas o grupos, para fines curativos y resilientes (Cramer, 1982: 1).

Las aplicaciones de intervención y mediación en ayuda humanitaria se han servido de muchas áreas del conocimiento y aplicaciones en campos prácticos. Entre ellas se encuentra el trabajo lúdico-artístico, que pone énfasis e incidencia sobre contenidos significativos para sus poblaciones objetivo, con actividades que reflejen valores y tradiciones de sus culturas (Simó-Alagado, 2013), siempre respetuosas y de acuerdo con las condiciones bio- $y$ psicosociales de estas personas y grupos.

Se preparan y exploran previamente los posibles diagnósticos del equipo profesional a cargo o de anteriores proyectos de intervención. Aunque no existan protocolos específicos de trabajo, base de posibles intervenciones $y$, aunque se utilice la intuición o la lógica de la experiencia, seguir estos pasos y condiciones permitirá un trabajo serio y responsable, coherente con la ética y profesionalismo que siempre deben estar presentes en estas prácticas.

Dentro del contexto de la intervención también forman parte del marco de atención de la asistencia humanitaria el equipo médico, psicológico, psiquiátrico, artístico, ocupacional, de asesoría legal, de protección militar, de voluntarios y otros. Estos equipos deben trabajar conjuntamente acompañando y dando apoyo diagnóstico, médico, psicológico, ocupacional, de asistencia social, legal y otros, a las personas durante las intervenciones humanitarias en contextos de conflicto armado y posconflicto (Simó-Alagado, 2013), y también fundamental en intervenciones y mediaciones con el teatro de títeres en estos contextos.

Por lo que respecta a este trabajo de investigación, es preciso mencionar brevemente algunas cuestiones sobre el rol y las perspectivas de acción de los profesionales que intervendrán a través del teatro de títeres con estos grupos de población. La comprensión del contexto y el grupo es un proceso que se debe hacer y continuar durante todo el proceso de trabajo con el teatro de títeres. Así mismo, se recomienda hacer una planificación previa y flexible como punto de partida, que dé luces sobre los objetivos, pasos y aspectos a desarrollar en el proceso de intervención y mediación con el teatro de títeres.

Por otro lado, el profesional que va a desarrollar un proceso de trabajo a través del teatro de títeres puede transferir su experiencia cuando ha realizado la creación de su propio títere y conoce de primera mano las posibilidades de materiales y técnicas que este le brinda. La experimentación de un proceso de libre expresión, exploración de la voz interna del títere y el espacio transferencial 
íntimo que se construye con el títere le aportarán al profesional herramientas de trabajo sensible para transmitirlo a otros (Tappolet, 1982: 116).

El profesional a cargo debe tener conocimiento sobre intervención en crisis, capacidad diagnóstica y clínica, conocimiento y propia vivencia con el teatro de títeres, que le permita llevar a cabo una intervención y mediación con este encaminado a la cura. Además, participará activamente, configurando el espacio ideal de trabajo, donde iniciar el juego con el títere; juego que pasa por todas las fases del teatro de títeres y del propio objeto-títere, comprendiéndolo y respetándolo; actúa como un observador participante, que impulsa los elementos de la psique del participante, y motiva los usos del lenguaje, la metáfora y la fantasía.

Para la acción de intervención y mediación con el teatro de títeres, en contextos de conflicto armado y posconflicto, el espacio del símbolo se mueve en el espacio de las interacciones. Packman (1994) infiere que ese es el contenido esencial del mensaje, tácito y emotivo, sobre el cual trabajar, en el que el profesional hace de lector-descriptor de dichas metáforas que contienen el símbolo, comunican e ilustran, idealmente, sobre lo que es importante ahondar, sin hacer conclusiones definitivas ni determinantes, ya que se entra en el terreno azaroso de las causas, que hace surgir las defensas del inconsciente y las culpas. Para Tappolet (1982: 29, 33), en ese proceso cada uno elabora su propia versión y experimenta las contradicciones y búsquedas por el largo camino de la expresión, por lo que es necesario evitar todo el tiempo las rotulaciones o los relatos concluyentes.

Durante el juego con el títere y su efecto catártico, el profesional elabora las realidades que emergen del inconsciente, dando giros de significados y significantes para restablecer el sentido al sujeto. Estas acciones son provocadas, interpretadas y dispuestas en un feedback de ida y vuelta con el paciente, como parte del proceso que aporta el teatro de títeres (Schon, 1979: 66).

El participante ya está preparado para entrar en el juego del teatro de títeres, su reservorio arquetípico y sus capacidades simbólicas le permiten seguir sus propias demandas, le recompensan con el placer del propio juego contrastando con las tensiones que le anteceden. El títere es el foco de atención del participante, actúa como un mediador que desvía la atención que el profesional ejerce sobre él continuamente (Salvage, 1988: 85).

El proceso de intervención y mediación con el teatro de títeres no sigue una ruta rígida, va adaptándose y salta de un lado a otro escuchando las necesidades de los participantes y el contexto, siempre con criterio profesional y hacia el desarrollo de los objetivos terapéuticos marcados. Aunque se haga un encuadre inicial del proceso con acuerdos organizativos y procesuales entre profesional y 
participantes, el desarrollo de la intervención y mediación con el teatro de títeres se va reinventado a sí misma, pero siempre con el sentido común de la reconstrucción humana para la vida de personas que han sufrido la violencia del conflicto armado y posconflicto.

\section{Reflexiones teóricas sobre procesos de intervención y mediación con el teatro de títeres}

Abordar una intervención y mediación con títeres implica tener en cuenta el contexto, la población y sus problemáticas. En el contexto propuesto para esta investigación, es importante clarificar sobre el tipo de conflicto armado y las implicaciones que tiene para el grupo humano afectado, el espacio en el que se va a trabajar, las condiciones físicas y humanas; así como reconocer y aprovechar en el proceso las habilidades y los conocimientos de las personas con las que se propone trabajar.

En cuanto al profesional, es fundamental saber sobre su formación y experiencia, el tipo de conocimiento disponible en el tema o área sobre el que va a trabajar; que tenga en cuenta el apoyo con el que cuenta, ya sea un supervisor, un equipo multidisciplinario o incluso las personas que acompañan al grupo de participantes y otros como vigilantes, militares, proveedores y visitantes de la zona (si fuera un centro de acogida, hospital, refugio, zona de guerra, etc.). Es necesario conocer de primera mano los apoyos familiares, amistades, redes sociales, religiosas, políticas, laborales y otras, con los que cuentan las personas que recibirán la terapia o la intervención (Hills, 2006).

También, la práctica terapéutica requiere de un encuadre que se articule sobre una propuesta de creación y una dinámica terapéutica que dote de sentido al proceso en su conjunto, si bien no directiva, sí con un enfoque profesional que oriente esta intervención $y$ mediación. Este encuadre supone un punto de partida desde el cual entender el proceso en sí y sus progresiones (Del Río, 2009).

El encuadre es un marco de acuerdos que establece el profesional para empezar un camino terapéutico con sentido delimitando un espacio de trabajo, determinando el contexto donde el terapeuta y paciente desarrollarán su proceso, acordando tiempos y normas, estableciendo el cómo y quién lo llevara a cabo, sobre la base de las condiciones y situaciones socioculturales de ambas partes (Granja, 2008: 134), en un clima que construya la confianza y la flexibilidad al cambio, capaz de adaptarse y entender las fluctuaciones u obstáculos que puede presentar el proceso.

Poner en marcha el proceso de intervención y mediación con el títere irrumpe en la realidad del individuo, se adentra en el tejido vital para generar una nueva trama, ya sea por revaluación, por 
resignificación o por transformación. Todas las capacidades y potencias humanas entran a usar la imaginación, la fantasía y el poder de la creación. Se remueven las capas de la experiencia para habitar un espacio que está por recrear.

Las subjetividades conscientes, preconscientes e inconscientes están listas para emerger a través de la ficción, y el lugar de la acción creativa propone nuevos referentes argumentando la nueva forma de concebir el mundo. Así mismo, hay que tener en cuenta que lo que se trata viene de un contexto conflictivo, cargado de dolor, culpa y vergüenza, y que las personas que lo viven tienen miedo a encontrarse con estos sentimientos y luchan para rehuirlos. Es importante entender que en este proceso no será tarea fácil aceptar la discrepancia, abandonar las verdades y contradicciones y encontrarse en la otredad propia del soy y quiero ser, así como verse a través de la alteridad, del otro, de la diferencia y del propio núcleo (Fiorini, 1995).

Es tarea del profesional seguir el hilo de ese recorrido, acompañar y recopilar la formación necesaria para armar los fragmentos que va dejando el inconsciente; leyendo entre líneas y pausas los silencios, los desplazamientos y progresos que tienen el individuo inserto en la intervención y mediación con el teatro de títeres. Los intermedios de ese proceso pueden promover la reescritura de un nuevo texto, la generación de la nueva poesía para interpretar la vida, ese imaginario significativo que despeja otros lugares para estar en el mundo.

Cada proceso creativo contiene el ser humano en su totalidad; la acción creadora es el movimiento de los cuerpos, de las ideas, de las emociones, de la existencia. Entra en acción la memoria, el pensamiento, el análisis, la composición, el volumen, la ubicación y todas facultades mentales básicas y superiores. Durante el proceso creativo se viven experiencias no concluidas, se expande la posibilidad bordearlas e ir y venir en la circularidad de la complejidad del ser, interminable e inagotable (Del Río, 2009: 23-24).

Por tanto, este proceso creativo interviene y media a través del títere en personas y grupos que han pasado por el conflicto armado, el cual les ha destruido los significados y los sentidos de vida. La acción creativa con el arte del títere, en relación con las conceptualizaciones y premisas de la salud sistémica y la paz imperfecta, ayuda al empoderamiento y la convivencia pacífica, con seres capaces y fortalecidos que usan sus propios recursos para generar bienestar para la vida en positivo y culturas de paz.

A manera de contextualización del arte como terapia, se hace referencia a un poco de historia que explica cómo nace, surge y se desarrolla el concepto de arteterapia. A principios del siglo XIX, el marqués de Sade ya dirigía espectáculos teatrales en su casa de salud de Charenton, hacía representaciones con los enfermos que podían 
durar cuatro o cinco horas. Ya en esa época, el teatro fue recomendado para que los enfermos mentales salieran de su apatía y su mundo interior oculto.

A finales del siglo xIX, los psiquiatras Mohr (1906), Simon (1876 y 1888) y Prinzhorn (1922) introdujeron la creatividad para los procesos de cura, que posteriormente publicarían como estudios sobre los dibujos y las pinturas de los pacientes con trastornos mentales (Fernández, s. f.). Adrian Hill, en 1942, acuñó el término arteterapia, después de convalecer por mucho tiempo en un sanatorio y, tras observar la evolución de su bienestar emocional y de los otros al realizar una actividad artística continua. De esa experiencia publica en 1943 su obra Art as an Aid to Illness: an Experiment in Occupational Therapy, y continúa sus escritos en 1945 con Art versus IIIness (Foro Iberoamericano de Arteterapia, s. f.).

Margaret Naumburg, en 1947, y Edith Kramer, en 1950, consolidan la práctica de la arteterapia con un enfoque psicoanalítico. Naumburg introduce la técnica del dibujo por asociación libre, en la búsqueda de un lenguaje que comunicara más allá de sus fronteras y avanzará hacía el insight. Kramer dio relevancia al proceso creativo y curativo del arte, permitiendo la sublimación y canalizando las energías en el objeto artístico. A mediados del siglo $\mathrm{xx}$, Harriet Wadeson, desde una perspectiva existencialista, utiliza el análisis y la reflexión verbal, después de la creación, para responsabilizar al paciente de sí mismo con el fin de dar sentido a su vida (Covarrubias, 2001: 5).

Posteriormente, con el interés de profesionalizar la arteterapia, en 1954 Volmat y Delay fundan el Centre d'Étude de I'Expression. Cinco años más tarde, nace la SIPE (Société Internationale de Psychopathologie de l'Expression), y más tarde, en 1964, aparece la Societé Française de Psychopathologie de l'Expression, en Francia, y la BAAT (British Association of Art Therapists) en el Reino Unido (Foro Iberoamericano de Arteterapia, s. f.). En 1969 se funda la AATA (American Art Therapie Association) en EE. UU. Finalmente, en 1991, la academia se implica con la arteterapia fundando el consorcio de universidades ECARTE (The European Consortium for Arts Therapies Education), que reúne a las universidades de Hertfordshire, Münster, Nijmegen y París, para regular y acreditar los estudios en terapias artísticas en Europa; la Universidad Complutense de Madrid y la Universidad de Barcelona se suman al consorcio para los estudios específicos de arteterapia. Desde 1999, en Gran Bretaña, la arteterapia cuenta con estatus y registro profesional, además de formar parte del sistema de sanidad del país (Foro Iberoamericano de Arteterapia, s. f.).

La British Association of Art Therapists (s. f.) precisa que aunque desde sus inicios está influida por el psicoanálisis, la arteterapia se complementa con otras teorías como la psicoterapia del apego, 
enfoques centrados en el cliente como el psicoeducativo, tratamientos basados en la atención plena y la mentalización, terapias centradas en la compasión y analítico-cognitivas. Sus aplicaciones también han estado muy comprometidas con prácticas en el área de lo social y a estudios de neurociencia y terapia. De acuerdo con Covarrubias (2001: 5), corrientes de orientación sistémica e integración teórica también aplican e investigan la arteterapia.

Del Río (2009: 18-19), recoge su naturaleza híbrida (arte y terapia) y la relaciona con fuentes que la nutren como la filosofía, la estética, la antropología, la sociología, la neuropsicología, la psicología, la educación, el trabajo social, la historia del arte, etc. Para la autora, dicha separación no implica una división o puja entre ambos conceptos; es necesario comprender la arteterapia como una disciplina compuesta y complementaria en la que cada territorio ocupa un espacio, una función y un tiempo, cuyo sistema se mueve entre lo relacional, lo intersubjetivo y lo transferencial.

Entre otras definiciones, y la que se aproxima más a este trabajo de investigación, la arteterapia es una forma de psicoterapia que utiliza el arte como su principal medio de expresión y comunicación para problemas emocionales, según la British Association of Art Therapists (s. f.); así mismo, menciona que su aplicación se puede aprovechar con personas que presentan dificultades, discapacidades, problemas emocionales, conductuales o mentales, enfermedades neurológicas y enfermedades físicas, pero no es una herramienta diagnóstica, una actividad recreativa, ni una lección de arte.

\section{Conclusiones}

En este apartado se presentan las conclusiones que surgieron de este proceso de investigación, que parte de la pregunta inicial: ¿Cómo y por qué el arte de los títeres promueve transformaciones positivas para la salud y la paz en contextos de conflicto armado y posconflicto?

Esta investigación presenta la práctica del teatro de títeres como un proceso complejo y amplio, aplicable en intervenciones y mediaciones profesionales que, desde la perspectiva de la complejidad y la psicología sistémica, den apoyo social y clínico a grupos poblacionales que sufren o han vivido el conflicto armado y posconflicto.

Las sinergias entre el arte de los títeres y la salud sistémica, con aplicabilidad en procesos de intervención y mediación con el teatro de títeres, se evidencian en sus procesos, postulados y objetivos. Estas conexiones tienen que ver con la creación de una virtualidad terapéutica de mediación y de juego, provocada intencionalmente 
por el profesional para actuar sobre la emergencia de una realidad difusa, fracturada y disgregada.

En el proceso de intervención sistémica y de mediaciones de paz con el teatro de títeres, se busca remover las experiencias emotivas para resignificarlas hacia nuevas maneras de percibir el mundo, de forma que para el sujeto se visibilizan las emociones y los sentimientos de impotencia, dolor y frustración, que le ha dejado la violencia del conflicto armado, en un feedback comunicativo empático, como efecto catártico.

La virtualidad del títere alivia al sujeto de la confrontación directa con su propio dolor, de su realidad precaria y violenta, eleva el deseo al lenguaje simbólico y activa conexiones cerebrales y mentales creativas, para liberarlo por medio de la expresión y la conciencia como sujeto empoderado.

La resignificación de la experiencia en esa virtualidad consiste en entender que las cosas son mientras signifiquen algo para el sujeto, por lo que el cambio se produce cuando la carga de significado para el sujeto es diferente y positiva. La virtualidad en este proceso reconoce la realidad del pasado y presente, pero crea realidades alternas más útiles y menos dolorosas. La producción de la virtualidad teatral es una zona de catarsis, de pruebas, de intercambios y reformulaciones en un espacio de vivencia $y$ convivencia ficcional que permite, en el terreno de la imaginación, que lo más inimaginable pueda ser posible.

Individualmente, en el proceso de intervención y mediación, el títere moviliza mecanismos psíquicos profundos e importantes para lograr integración de un yo fracturado por la violencia. Este proceso se inicia con la identificación progresiva del sujeto con el títere, construyendo la coherencia entre lo afectivo, emotivo, corporal, racional e intelectual. Esta identificación luego se proyecta en el títere como una imagen estable de un doble-yo estructurado, como nueva subjetividad que reactiva la vida psíquica del individuo y accede a zonas no habituales del pensamiento, donde las cosas creadas cambian de significado. Un yo integrado en el sujeto conforma la identidad que guía el libre pensamiento; este ser, a través del doble, es otro ser reconocido y renovado.

En definitiva, un proceso de intervención y mediación con los títeres, desde la perspectiva del arte de los títeres, la psicología sistémica y la paz imperfecta, aporta a personas que han vivido la fuerza destructiva del conflicto armado la posibilidad de:

i. Identificar los elementos de emergencia que ha provocado el conflicto armado.

ii. Promover los recursos y las actitudes para estimular la expresión de la creatividad, para la imaginación de nuevas realidades. 
iii. Estimular procesos catárticos de expresión de emociones, sentimientos de la propia experiencia de dolor, para resignificarlas y reajustarlas.

iv. Permitir la identificación y proyección de los fragmentos del yo, para su integración y recomposición.

v. Fomentar la toma de conciencia resiliente de los propios recursos, capacidades y potencialidades, para la acción en positivo.

vi. Restablecer la integridad y la identidad de las personas y el grupo, desde donde configurar nuevos valores $y$ sentidos.

vii. Potenciar la creación de estrategias o pautas de acción para la transformación de la realidad, hacia aquellas imaginadas.

viii. Consolidar las propias metas y los objetivos colectivos, que se dirijan hacia el empoderamiento pacífico y el bienestar para la vida.

ix. Fomentar la toma de conciencia social, para la consolidación de ciudadanos políticos, críticos, autocríticos y participativos.

American Psychiatric Association. 2013. DSM-5: Manual Diagnóstico y Estadístico de los Trastornos Mentales. España: Editorial Médica Panamericana S.A.

Bennegadi, Rachid. 2016. "Tiempo de resiliencia: Las heridas de los refugiados». El País: Suplemento Ideas, 27 de marzo, 1-2.

Berk, Jay (1998): «Trauma y resiliencia durante la guerra: una mirada a los niños ya los trabajadores de ayuda humanitaria en Bosnia». Revista psicoanálisis, Asociación Psicoanalítica de Buenos Aires, 24 (1): 2. Acceso del 31 de julio de 2016. http://www.apdeba.org/wp-content/uploads/berk.pdf.

Covarrubias, Thusnelda. 2001. Arte terapia como herramienta de intervención para el proceso de desarrollo personal. Santiago de Chile: Pontificia Universidad Católica de Chile.

Cramer, Bertrand. 1982. Prólogo. En Las marionetas en la educación: la muñeca de la nariz menuda, editado por Ursula Tappolet. Barcelona: Científico Médica.

Cyrulnik, Boris. 2016. "Tiempo de resiliencia: nadie sabe definir la felicidad». El País: Suplemento Ideas, 27 de marzo, 4. 
del Río, María. 2009. "Reflexiones sobre la praxis en arte terapia». Revista Arteterapia - Papeles de arte terapia y educación artística para la inclusión social 4: 7-26.

Fiorini, Héctor J. 1995. El psiquismo creador. Buenos Aires: Paidós.

Granja, Gladys. 2008. La terapia familiar sistémica. Cuenca, Ecuador: Universidad Politécnica Salesiana.

Hills, Margaret. 2006. "Reflexión sobre terapia y niveles de intervención terapéutica». En Seminario: Visiones y aplicaciones en el campo del Arte Terapia, 21, 22 y 23 de julio. Universidad de Chile.

Packman, Marcelo. 1994. Introducción al pensamiento complejo. Barcelona: Gedisa.

Peñas-Felizzola, Olga Luz, et al. 2015. «Participación de terapia ocupacional en contextos de conflicto armado y postconflicto». Revista de Salud Pública 17 (4). Acceso del 31 de julio de 2016. http://www.scielosp.org/pdf/rsap/v17n4/v17n4a11.pdf.

Rodríguez, Clemencia. 2008. "Lo que le vamos quitando a la guerra: medios ciudadanos en contextos de conflicto armado en Colombia». Centro de Competencia en Comunicación para América Latina, Friedrich Ebert Stiftung, (5). Acceso del 31 de julio de 2016. http://library.fes.de/pdf-files/bueros/c3comunicacion/07330.pdf.

Salvage, Pierrette. 1988. La marionnette structurant spatial: dans le cadre de la rééducation psychomotrice. París: Université Paris VI.

Schon, Roland. 1979. La marionnette du theatre a la thérapie: mémoire de Psychiatrie. Tesis doctoral. Université Paris 5 - René Descartes. http://www.takey.com/Thesis_232.pdf.

Tappolet, Ursula. 1982. Las marionetas en la educación: la muñeca de la nariz menuda. Barcelona: Científico Médica.

The British Association of Art Therapists. Acceso del 18 de septiembre de 2016. http://www.baat.org/About-Art-Therapy. 